\title{
Continuity and discontinuity between psychopathology of childhood and adulthood: a review on retrospective and prospective studies
}

\author{
Immacolata Zarrella, ${ }^{1}$ Luigi Alessandro Russolillo, ${ }^{2}$ Giorgio Caviglia, ${ }^{2}$ Raffaella Perrella ${ }^{2}$ \\ ${ }^{1}$ Department of Social and Developmental Psychology, Sapienza University of Rome, Rome; ${ }^{2}$ Department of Psychology, University \\ of Campania Luigi Vanvitelli, Naples, Italy
}

\begin{abstract}
The knowledge of the possible development of a psychiatric disorder, diagnosed for the first time in childhood, is very crucial for all specialists in helping professions working with children and adults. Recent longitudinal studies have demonstrated the possibility that disturbances in childhood may increase the risk of psychiatric illnesses in adulthood, through a homotypic or heterotypic continuity. The aim of this study is to perform a systematic review of existing literature on the psychopathological progression from childhood to adulthood, taking into account both prospective and retrospective studies, and the antecedents and conditions that may encourage/disadvantage the process of continuity of psychopathological syndromes. The study of the possible trajectories of psychopathological disorders is considered fundamental, as it allows the clinician to configure prevention strategies and evaluate interventions, but also to offer to the parent a more concrete vision of the possible risks of their child's disorders to minimize them.
\end{abstract}

Key words: Psychopathology; Childhood; Adulthood; Retrospective studies; Prospective studies.

\section{Introduction}

In recent years, research aimed at understanding the relationship between childhood and adulthood psychopathology has increased significantly (Siracusano \& Rubino, 2010; Caviglia \& Zarrella, 2011, 2013). Many studies (Castagnini, Foldager, Caffo \& Thomsen, 2016; Copeland, Wolke, Shanan \& Costello, 2015; Hofstra, Van der Ende \& Verhulst, 2002) have been undertaken not only to determine the need for early, preventive interventions, but also in

Correspondence: Immacolata Zarrella, Department of Social and Developmental Psychology, Sapienza University of Rome, Rome, Italy.

Email: immacolata.zarrella@uniroma1.it

Citation: Zarrella, I., Russolillo, L.A., Caviglia, G., \& Perrella, R. (2017). Continuity and discontinuity between psychopathology of childhood and adulthood: a review on retrospective and prospective studies. Research in Psychotherapy: Psychopathology, Process and Outcome, 20(2), 101-109. doi: 10.4081/ripppo.2017.248

Received for publication: 27 November 2016.

Revision received: 19 April 2017.

Accepted for publication: 22 April 2017.

This work is licensed under a Creative Commons Attribution NonCommercial 4.0 License (CC BY-NC 4.0).

CCopyright I. Zarrella et al., 2017

Licensee PAGEPress, Italy

Research in Psychotherapy:

Psychopathology, Process and Outcome 2017; 20:101-109

doi:10.4081/ripppo.2017.248 order to validate or dismiss the belief of a hypothetical generation gap between the disorders of childhood and adulthood disorders. This viewpoint, which developed from the traditional division of psychopathology by age, had determined that childhood disorders were mainly considered as transient adjustment disorders (Siracusano \& Rubino, 2010). However, the results of the latest scientific works have led many researchers to support the unified hypothesis of classification concerning psychopathology (Hofstra, Van der Ende \& Verhulst, 2002; Labey, 2015), according to which both childhood and adulthood disorders can be considered prospectively linked - and sometimes overlapping - clinical pictures. The unified hypothesis, along with the evaluation that a childhood disorder may represent a possible antecedent of a disorder in adulthood, presupposes a maintenance or progression of the disorder itself; in other words, a continuity or discontinuity of the same disorder over the course of life (Siracusano \& Rubino, 2010).

The possibility to validate this theoretical assumption comes from the virtual revolution (Rutter, Kim-Cohen \& Maughan, 2006) of research of the last twenty years and the theoretical approaches that consider the hypothesis of psychopathological continuity/discontinuity a necessary element in the clinical process of diagnosis and prognosis concerning infants and adults; but also, and above all, from the results of recent epidemiological analyses and longitudinal studies, extended from childhood to adulthood, which validated the hypothesis that disorders can follow a homotypic or heterotypic continuity, or discontinuities during the development. Generally, in these studies homotypic continuity is used if the psychopathological development is simple, so that a diagnosis of a particular disorder in childhood remains unchanged until adulthood. 
This suggests the idea that a single disorder (almost all, except Phobia, and especially: Panic Disorders, Psychosis, Pervasive Developmental Disorders, Depressive Disorders and Anxiety Disorders - especially in girls -, Tic disorders, Encopresis, Enuresis - only in boys - and Substance Use Disorders) can be expressed in different contexts of development and remain stable until adulthood (Costello et al., 2003). In heterotypic continuity, however, a change in diagnosis occurs from childhood to adulthood, that probably reflects the phenotypic expression of a specific, general psychopathological process, in different developmental contexts. This variety is receiving a significant experimental support and appears to be more widespread than homotypic continuity (Lahey, Zald, Hakes et al., 2014). This is the case of Anxiety Disorders, which tend to develop in Depressive Disorders or vice versa, and Oppositional Defiant or Conduct Disorders that precede anxiety and depression (Copeland et al., 2009), Personality Disorders (Helgeland, Kjelsberg \& Torgersen, 2005) and Bipolar Disorders in adulthood (Levi \& Romani, 1999).

Alternatively, discontinuity is used in the event that a child with a psychiatric diagnosis becomes a mentally healthy adult (Turk et al., 2007).

So, taken together, the homotypic continuity appears to be common to a number of disorders, while heterotypic is limited to a few development paths. Long term longitudinal studies on wide samples (Caspi, 2000; Castagnini et al., 2016; Copeland et al., 2009, 2015; Costello, Mustillo, Erkanli, Keller \& Angold, 2003; Kasen, Cohen, Skodol, Johnson \& Brook, 1999) have shown, in fact, that many disorders, first diagnosed in infancy, increase threefold the risk of adverse outcomes in late adolescence and in adulthood compared to disorders with later onset, and can develop into chronic and stable pathologies. Furthermore, there seems to be a significant correlation between childhood and adulthood also if we include impairments in some areas of functioning (social, occupational, relational, etc.) and the presence of subthreshold symptoms in childhood (Copeland et al., 2015).

In the present work, we will focus on the methodological differences between some different research models and types of studies which were used to investigate (directly or indirectly) the psychopathological continuity/discontinuity from infancy to adulthood - in other words, retrospective and prospective studies; the plausible evolutionary pathologic paths of infancy disturbances, with particular reference to adult personality disorders, and, finally, the antecedents and conditions mainly highlighted by retrospective studies that could foster or not the maintenance of the disorder from infancy to adulthood.

\section{Longitudinal studies in research}

In general, longitudinal studies that explore the continuity/discontinuity of a disorder are divided into retro- spective, prospective and combined studies (Loeber \& Farrington, 1997).

The first retrospective studies on psychopathological continuity can be traced to the psychoanalytic childhoodback-adulthood investigations, on patients with adult psychiatric pathologies (Siracusano \& Rubino, 2010). Empirical evidence (Kim-Cohen et al., 2003) indicates, in fact, that most of the patients in psychiatric treatment report a homotypic or heterotypic progression of the disorder from early childhood or adolescence to adulthood: Maughan and Kim-Cohen (2005) have shown, for example, that 25 to $60 \%$ of adults with psychiatric disorders had a Conduct Disorder in childhood, not diagnosed previously.

Retrospective studies evaluate, through interviews and self-report, the progress of psychopathology from childhood to adulthood, taking into account the individual's or his family's reconstructions or earlier clinical investigations. In restrospective methodologies, it is possible to distinguish between follow-back studies, in which the samples are divided according to the information gathered, and catch-up studies, in which the collected data will classify the samples for subsequent prospective investigation (combined studies). Generally, catch-up or combined studies would seem more appropriate than follow-back ones in research on continuity, as they allow to estimate prospective possibilities on the basis of the subject's background (although they still do not provide significant information on the onset of the original disorder). The follow-back studies, however, can be very useful in investigating rare phenomena that cannot be studied prospectively (Loeber \& Farrington, 1997). In addition, both studies are very convenient when the research hypothesis is designed to observe the relationship between possible risk factors and onset of a disorder. In fact, most of the retrospective studies in literature highlights interesting clinical observations on the relationship between specific risk factors in childhood and onset of psychopathology in adulthood (Rubino, Nanni Croce \& Siracusano, 2008). The reasons underlying the continuity or discontinuity of a disorder, in fact, can be multiple and variable. Their conceptualization depends, first, from the theoretical frame used: generally, referring to different theoretical approaches, it is possible to speak of genetic, neurobiological, post-traumatic (Levi, Romani, 1999) or psychosocial (Rutter, 2005) mechanisms. Many authors (Johnson et al., 2006; Lewis, 2002; McLean \& Gallop, 2003; Turk et al., 2007) agree in considering certain life events, the so-called risk factors, extremely dangerous for the child's development. Risk factors refer to all existential conditions of the child and his environment which imply a higher risk of psychopathology than that observed in the general population. According to Rutter (2005), the risk factors would appear to operate also in normal environments, and not only in extreme ones; they can affect the individual in childhood, as well as in adulthood, and can interact with 
the development also in the pre- or post-partum phases. From a psychopathologic point of view, without a theoretical frame of reference, it is possible to list a number of biological and environmental risk factors, that increase the likelihood of child running into severe and disabling psychopathological disorders during development. The current knowledge on the biological factors of behavior has allowed some clarification on the relationship between mind and brain, and between disorders of brain development and disorders of mental functions (Surian, 2002). The methods of behavioral genetics (family, twin, and adoption studies), studies of neuroanatomy, neurochemistry and neurophysiology on certain mental disorders and the recent research on molecular genetics have, in fact, revealed numerous differences in brain functions and features of individuals with psychiatric disorders. Although the search for specific molecular abnormalities or biochemical markers, in fact, has not been successful for child psychiatry (Alsobrook et al., 2002), where mental disorders seem to have a multifactorial origin, it would seem most promising the use of genetic linkage analysis (ivi). Linkage is the tendency of neighboring genes, on the same chromosome, to be transmitted together during cell meiosis, and, therefore, to be inherited from parents to children. The linkage analysis allows, therefore, to estimate the frequency of recombination between the two genes and, in summary, to identify the chromosomes responsible for potential pathologies (Alsobrook et al., 2002). The scientific results are, in fact, still very controversial, and although the genetic differences may explain the 40 or 50 percent of the individual variability, they should not be divided from the influence exerted by the environment. On the other hand, retrospective studies cannot rule out the possibility that the association between risk factors and psychopathology derives from mnemonic errors or pre-existing pathological traits that may have contributed to the onset of certain childhood adversities (Maughan \& Rutter, 1997). It must be remembered, however, that the test-retest stability of many works has provided a reliable basis to overcome the difficulties of validation of adults' traumatic memories, even in the case of adults with severe psychiatric disorders, allowing to take better in account the results of retrospective research (Rubino et al., 2008). Nevertheless, such observations only provide a general estimate of the psychopathological progression of a disorder, as they do not take into account the lack of reliability of the accounts exposed by the patient, the repeated comorbid disorders and the possibility of a heterotypic continuity of the disturbance in the development.

Recent prospective or childhood-to-adulthood research (Caspi, 2000; Copeland et al., 2009, 2015; Costello et al., 2003) focused on data analysis of longitudinal and epidemiological studies on childhood, appear more promising for research on continuity. Overall, these studies have documented the probability that a disorder, diag- nosed for the first time in childhood, may develop into a chronic and stable disease.

Currently, prospective studies are legitimately considered the only reference points to rely on in continuity research (Turk, Graham \& Verhulst, 2007). They have, in fact, a number of advantages, including the ability to choose what measures to use to evaluate specific cases of psychopathological progression in specific periods of development. One of the few disadvantages of such studies is that most of them do not use birth-cohort, i.e. samples of subjects followed from the time of birth. Therefore, these studies lack good results regarding the early development of the behavior (Cicchetti, 2010). To overcome this issue, combined studies were conducted, as these add retrospective information, useful in classifying the sample under examination, to the prospective studies. Combined studies, however, are of limited use in the study of risk factors that occur before the first instant of the work's measurement. Even if they allow, in fact, to take into account the constant risk factors in the development, by collecting retrospective information, it must be noted that many risk factors may vary over time and thus need to be always evaluated prospectively.

Finally, Cicchetti (2010), in the analysis of data from two studies, one of which is prospective - the Dunedin Study - and the other retrospective - the Wirral Woman's Health Survey - noted the significant coherence of the results of both studies. The prospective research has offered more reliable and accurate data, but the results remained the same no matter how.

\section{Results of prospective studies}

The following are the experimental results and a review of prospective studies on the continuity/discontinuity in correlation to some usually diagnosed in childhood disorders: Mood Disorders, Behavioral Disorders, Anxiety Disorders, Eating Disorders, Dissociative Disorders and Personality Disorders.

\section{Mood disorders}

The Dunedin Study (Caspi, 2000) documented a diagnostic specificity of affective disorders throughout the cycle of life, showing a high homotypic correspondence. The results of Copeland and colleagues (2015) reported, however, an attenuation of such homotypic predictiveness and an even more significant decline in the same continuity between depressed children and depressed adults. This could suggest, according to the authors, that the apparent association between depression in adolescence and depression in early adulthood is an epiphenomenal association, resulting from direct associations between adolescent comorbid disorders and subsequent depressive syndrome. Therefore, the heterotypic correlations between a diagnosis of Major Depressive Disorder (MDD) in childhood and a 
later onset of Generalized Anxiety Disorder, or a Panic Disorder without Agoraphobia, or even Agoraphobia without history of Panic Disorder in adulthood seem more relevant. Other longitudinal studies have demonstrated, moreover, the link between MDD and Cluster C Personality Disorders in adulthood, especially among women (Helgeland et al., 2005; Kasen et al., 2001).

\section{Behavior disorders}

Despite the concrete possibility of homotypic predictiveness in Behavior Disorders from childhood to adulthood (Copeland et al., 2009, 2015), these syndromes can also flow into Personality Disorders (Helgeland et al., 2005; Sartor \& Salcuni, 2017); in affective disorders such as Major Depression, Dysthymia and Bipolar Disorder; in Anxiety Disorders or in a Substance Use Disorder in adolescence and early adulthood (Copeland et al., 2009, 2015; Costello et al., 2003). The results of the Dunedin Study analyzed by Caspi (2000) on children classified as difficult, characterized by impulsiveness, irritability and lack of emotional regulation, validate these rates of predictability, although the author also underlines the high rate of discontinuity in this group. In this regard, also Copeland and colleagues (2015) prefer to speak in terms of predictability, rather than continuity, as no longitudinal study can capture the real continuity of a disorder: the experimental observations in these studies are, in fact, intermittent and not continuous.

\section{Anxiety disorders}

According to Ferdinand and colleagues (2007), Separation Anxiety Disorders and Generalized Anxiety Disorders in childhood entail Social Phobia in adulthood, while the Social Phobia and Panic Disorder would be characterized by a more persistent homotypic continuity. Regarding the Obsessive-Compulsive Disorder (OCD), it would seem to follow commonly an intermittent course, but more protracted than the other Anxiety Disorders. In addition, there is evidence of a heterotypic predictiveness between OCD and Avoidant Personality Disorder, Anorexia Nervosa and Paranoid, Schizotypal and Schizoid Personality Disorders in adulthood (Kasen et al., 1999, 2001). The correspondence between OCD in childhood and Obsessive-Compulsive Personality Disorder in adulthood is ascertained, but not always the first is a necessary antecedent to the onset of the latter (Levi \& Romani, 1999). Biological origins could explain, however, the alleged homotypic continuity of Post-Traumatic Stress Disorder. Some individuals seem, in fact, more prone to this disorder because of abnormalities in neuromodulatory systems that would lower the levels of cortisol in circulation (Bleiberg, 2004). This syndrome, could also lead, later in life, to Substance Use Disorders, Behavioral Disorders and ADHD, Dissociative Disorders, Sleep Disorders, Somatoform Disorders, Borderline or Paranoid
Personality Disorders (Golier et al., 2003). Most researchers, however, agree in considering more common a discontinuity of anxiety disorders between childhood and adulthood rather than a continuity (Caspi, 2000; Ferdinand et al., 2007; Turk et al. , 2007). In fact, the results of Copeland and colleagues (2009) reported a match between Overanxious Disorders (classified in the DSM-IIIR) in children and Generalized Anxiety Disorders, Social Phobia, Depression and Conduct Disorders in Adolescence, but not in adulthood.

\section{Eating disorders}

As for Eating Disorders there seems to be no evidence of their continuity in adulthood, although Merycism may be present in cases of Anorexia and Bulimia Nervosa in adolescence. Regarding the Avoidant/Restrictive Food Intake Disorder, recently included in the DSM-5, only limited data is available to formulate a causal link between this disorder and an Eating Disorder in adulthood (APA, 2013). In contrast, Infant Anorexia (Ammaniti, Lucarelli, Cimino \& D'Olimpio, 2008) seems to persist, from early childhood, more or less permanently, even with heterotypic trajectories that lead to internalization syndromes, Separation Anxiety Disorder, depressive symptoms, Phobia and oppositional behavior. In a meta-analysis, Turk and colleagues (Turk et al., 2007) report, however, that results of longitudinal studies on Eating Disorders are mostly on adolescent samples. Anyway, these studies highlight an insignificant homotypic continuity to Anorexia Nervosa (AN). Heterotypic predictiveness, however, seems to be more evident: adolescents with Eating Disorders tend to suffer in adulthood of Anxiety, Depressive, Personality Disorders and suicidal attempts (Johnson, Cohen, Kasen \& Brook, 2002). The correlation between $\mathrm{AN}$ in adolescence and OCD in adulthood can also be interpreted as a co-occurrence of the obsessive spectrum with an Eating Disorder (Anderluh, Tchanturia, Rabe-Hesketh \& Treasure, 2003). More relevant, however, seems to be the connection between AN With Restrictions and Obsessive-Compulsive, Schizoid, or Avoidant Personality Disorders and between AN with Binge-eating/purging behaviors and Borderline Personality Disorder (Torres Pérez, Del Rio Sanchez \& Borda, 2008). Furthermore, BPD would seem more linked to Bulimia Nervosa, the Eating Disorder that always has onset in adolescence, and is quite rare before age 14 (Caviglia et al., 2010). In a meta-analysis about childhood obesity, Biro and Wien (2010) have shown the association of pediatric and adolescent obesity with obesity in adults. Overweight children are more prone to becoming overweight adults, especially at higher BMIs or if they have an obese parent.

\section{Dissociative disorders}

Some longitudinal studies (Jans et al., 2008) show a greater discontinuity rate of dissociative disorders from childhood to adolescence, probably due to individual vari- 
ability (Perrella, Del Villano \& Caviglia, 2016) and the possibility of timely psychiatric treatment, and a significant prevalence of heterotypic continuity from early adolescence to adulthood. Young people with dissociative disorders seem to be, in fact, more prone to Anxiety, Depressive or Somatoform Disorders and Borderline, Obsessive-Compulsive, Avoidant, Paranoid and Antisocial Personality Disorders.

\section{Personality disorders}

Although empirical evidence documenting the presence and continuity of these disorders in childhood is, to date, relatively scarce and many clinicians are still reluctant to apply such diagnoses in childhood (Turk et al., 2007), an increasing number of evidences is appearing in literature, thus stating its plausibility (Bleiberg, 2004), especially for Borderline Personality Disorder (BPD), probably because of its diverse characterization of symptoms, comparable to that of the other Personality Disorders. For this reason, it is preferable to use Borderline Pathology of Childhood (BPC), instead of a real BPD diagnosis in childhood. This condition would be characterized by a series of impairments in the child's overall functioning (social, emotional, cognitive, neurophysiologic areas), attributable, however, to different Personality Disorders (PD). Caspi (2000) has found the presence of specific symptoms and predictors of serious Personality Disorders in adulthood in children of three years: impulsive symptoms appear to predict Personality Disorders in adolescence and impulsive PDs in adolescence would involve major diseases in adulthood. In this case, the problem of little observable chronicity and stability of PD in childhood would be solved within the continuity of some specific symptoms, defined as traits or psychopathological dimensions, such as, for example, impulsivity (Lewis \& Volkmar, 2002 Perrella, Caviglia \& Semerari, 2013). A recent meta-analytic review of the data in literature carried out by Deschamps and Vreugdenhil (2008) found, in fact, a significant heterotypic continuity, in 80 percent of cases, between BPD in childhood and other PD in adulthood, and a homotypic continuity of BPD only in 16 percent of cases. The authors suggested that some symptoms of BPD remain stable from childhood to adulthood (feelings of emptiness, anger, emotional instability and identity problems), while the most characteristic (self-injury, instability in relationships, impulsivity, derealization, paranoid ideation) show a discontinuity. In fact, recent works (Zanarini et al., 2003), based on a category approach, have detected a certain instability of the PD in adulthood and only the severity and comorbidity with other syndromes seem to determine its chronicity (Skodol et al., 2007; Zanarini et al., 2003). According to Skodol and colleagues (2007), in fact, the stability of a PD is indirectly proportional to the distance between the various follow-ups of a longitudinal research. The greater the distance, the lower the stability of the disorder evaluated by the research. Studies that have looked at Personality Disorders in a di- mensional perspective, report, nonetheless, a high stability and chronicity (Lenzenweger, 1999). To date, therefore, the prognostic evolution of these disorders continues to appear rather uncertain (Lewis \& Volkmar, 2002).

\section{Results of retrospective studies: antecedents and conditions of continuity}

Retrospective studies have offered a lot of empirical evidence about the possible relationship between risk/protective factors (abuse, loss, abandonment, deficits in parenting, poverty, etc.), genetic influences and continuity/discontinuity of a disorder (Mikolajewski, Taylor, \& Iacono, 2017; Rubino et al., 2008). In addition, many authors (Johnson et al., 1999a, 1999b, 2006; Levi \& Romani, 1999; Lewis \& Volkmar, 2002; McLean \& Gallop, 2003; Turk et al., 2007) agree that some events are extremely dangerous for the child's development. For this reason, the search of retrospective studies for antecedents and mechanisms underlying the onset and maintenance of psychopathology is constantly focusing on those negative experiences that perpetuate their adverse effects in child development, thus becoming chronic adversity in adulthood. Among these conditions, the worst is surely the abuse.

\section{Physical/sexual abuse}

Many retrospective studies (Bulik, Prescott \& Kendler, 2001; Golier et al., 2003; Johnson et al., 1999b, 2006; McLean \& Gallop, 2003; Turk et al., 2007) have documented in adult psychiatric patients the presence of cases of abuse during childhood: many adult with Behavioral, Attention (ADHD), Anxiety, Affective and Substance Use Disorders report, in fact, to have been subject to abuse and mistreatment in childhood and/or early adolescence. Also the relationship between physical abuse in childhood and Personality Disorders in adolescence and early adulthood has been significantly investigated and confirmed (Golier et al., 2003; Johnson et al., 1999b, 2006; McLean \& Gallop, 2003). In addition, Kent, Waller \& Dagnan (1999) have underlined many cases of emotional, physical and sexual abuse even in patients with Eating Disorders; Bulik and colleagues (2001), based on the severity of sexual abuse, have described the occurrence of specific psychiatric disorders, including Use of Substance Disorder and Eating, as the main effects and results of abuse.

\section{Inadequacy of parenting functions}

Many authors (Del Villano, Perrella, Bisogno, \& Caviglia, 2014; Lewis \& Volkmar, 2002; Stein, Lehtonen, Harvey, Nicol-Harper \& Craske, 2009; Turk et al., 2007; Zarrella, Lonigro, Perrella, Caviglia \& Laghi, 2016) especially agree in considering the effects of parental deficits as significant predictors of attentional, linguistic and emotional difficulties in the child, and, therefore, of Learning, Behavioral and affective regulation disorders 
later in life. As for psychiatric disorders, the correlation between disorders in parents and disorders in offspring appears to be significant, but not as much as we might imagine (Minde \& Minde, 2002). Even in this case, the presence of conflicts and side effects of the psychopathology seem to be more risky than the mere presence of the disease, unless it is present in both parents. In the latter case, in fact, the risk of onset of a psychiatric disorder in sons is much higher. Maternal depression, in particular, is a significant predictor of Affective, Somatic and Behavioral Disorders, and growth retardation in offspring, both in childhood and adulthood (Minde \& Minde, 2002; Turk et al., 2007). Also, substance abuse and/or alcohol use by parents are significant predictors for diminished emotional skills, dissociative experiences, increased aggressiveness and reactivity to stress in children (Elkins, McGue, Malone \& Iacono, 2004). Moreover, the risk that these children can reproduce these behaviors in adulthood is very strong (Elkins et al., 2004; Minde \& Minde, 2002), especially if, in the parents, the Substance Use Disorder is comorbid with an Antisocial Personality Disorder (Moss, Lynch, Hardin \& Baron, 2002).

\section{Loss, abandonment and institutionalization}

The experience of loss in childhood, especially if related to the loss of a parent, can be a strong risk factor for subsequent onsets of psychopathology (Weller et al., 2002). Depression, Anxiety (especially in early childhood, more than in adolescence) and Behavioral Disorders seem to be the most frequent disorders in the first few months after the tragic event and, in many individuals, appear to persist in adulthood. Abandoned and institutionalized children seem to be particularly predisposed to Learning Disorders and criminal activities in adulthood (Minde \& Minde, 2002).

\section{Disasters}

A recent study by Dunn, Nishimi, Powers and Bradley (2016) revealed an increase of PTSD symptoms in children exposed to early trauma: the younger they are, the greater the incidence of depressive and PTSD symptoms, that last even in adulthood. Moreover, younger children can suffer from behavioral regression, extreme dependency, fear, PTSD, Affective and Sleep Disorders and increased aggressiveness; in older children, consciousness disorders, dissociative and depressive symptoms can occur, although being more temporary. Kar and colleagues (2007), in a study on the psychological reactions of children and adolescents one year after a severe cyclone in India, have found that, over time, the major risk factors for the maintenance of PTSD symptoms were a high exposure to the cyclone and low education and socio-economic level, rather than events such as the loss of family members, the damage to their homes, and fear of the catastrophic event.

\section{Poverty}

Poverty is a very invasive risk factor, although it is mainly a distal factor, the effects of which can interact with parental care, invalidating it (Minde \& Minde, 2002), or characterize social experiences of the child, which could increase relations with deviant peers (Wolff, 2002). Hyperactivity, impulsivity, ADHD and Behavior Disorders often emerge in children living in situations of economic and social deprivation (Lewis \& Volkmar, 2002). The rate of Substance Use Disorders seems very high because of these conditions, both among parents and among their children (Minde \& Minde, 2002).

\section{Protective factors}

Retrospective studies, initially focused on finding stressful events in the life of individuals with psychopathological disorders, also detected that some mechanisms, defined as protective, of constitutional or environmental nature, could promote a better adaptation of the individual to stressors. The reason why trauma, abuse, maltreatment, abandonment, negative family experiences, poor parenting, poverty, seem to intercede in the development pathway of some children and break it, while in others cause only temporary abnormal reactions (Lewis \& Volkmar, 2002; Turk et al., 2007) could be explained, not only by different traumatic episodes, but also by the interactions between risk and protective factors. According to Rutter (2005), there are various factors that promote resilience and allow the child, in a position of vulnerability, to cushion and/or overcome the stressors determined by the risk factors. Furthermore, resilience is not the only protective factor: even positive experiences, previous or consecutive to the onset of risk factors and/or lack of genetic predispositions to the vulnerability to environmental hazards have a major impact in the onset and maintenance of a disorder (Turk et al., 2007).

\section{Conclusions}

The study of psychopathological continuity and discontinuity has a complex and difficult objective, since it aims to find a psychopathological progression which consists, instead, of variables and multiple and articulated underlying processes, often not immediately clear nor evident. Knowing the possible development of a psychiatric disorder, diagnosed for the first time in childhood, however, remains crucial for all professionals working with children (Turk et al., 2007). First of all, this competence allows the clinician to configure in his mind, although only in theory, the various psychopathological trajectories to evaluate their therapeutic and preventive interventions in order to offer, even to the parent, a more concrete vision of the psychopathological progression of the disorder. Secondly, even the smallest therapeutic success with a child could be useful and beneficial for his fu- 
ture health, considering the severity of certain disorders of adulthood. According to several studies (Kim-Cohen et al., 2003; Maughan \& Kim-Cohen, 2005), in fact, 25$60 \%$ of adults with psychiatric disorders had a Conduct Disorder in childhood not promptly diagnosed and treated. On the other hand, the results of retrospective studies of adults should not be considered the only criterion to refer to (Turk et al., 2007). Retrospective studies allow to highlight some of these mechanisms, promoting a greater focus on all those risk and protective factors that affect the continuation or the ending of a disorder during development. These studies would seem, therefore, very advantageous when the research hypothesis is designed to observe the relationship between possible risk/protective factors and eventual onset/maintenance of a disorder from childhood to adulthood. Abuse, family conflict, neglect, loss, institutionalization, seem to be significantly related to a chronic continuity of disorders; as, in some cases, protective factors seem to promote, instead, a discontinuity. However, a recent study (Weibel, Vidal, Olié et al., 2017) showed, for example, that internalized psychopathology (depression, hopelessness and low self-esteem) is the main mediator of the impact of childhood trauma on meaning in life in adult with persistent a psychiatric disorder. The relation between trauma and meaning in life, therefore, is indirect and mediated by actual mood symptomatology and self-esteem. In general, then, it would seem that the risk factors have no direct effect on psychopathological continuity.

Furthermore, the difficulties and the methodological limitations of retrospective research, compared to the prospective studies, do not always allow to obtain generalizable data, despite several comparative analyses have shown a definite overlap of the results of both these types of research. The prospective method appears, therefore, more promising, although even in these studies, except for a few specific cases (as for Conduct Disorders, Pervasive Developmental Disorders, Schizophrenia), the process that underlies the consequentiality of phenomena is unclear, at the best.

From a clinical point of view, the continuity may be present because the psychopathological process is internalized, and is therefore impermeable to external changes or, vice versa, the risk factors perpetuate the maintenance of the disorder (for example, social circumstances) because of their generally stable nature. In the latter case, the diagnosis of continuity would be only a reflection of the persistence of adversity; as a consequence, if this persistence vanishes, so does the disorder.

A substantial number of methodological issues, however, weakens these hypotheses. First of all, many studies fail in predicting disorders, as they don't consider the relevant changes that occur during adolescence. Adolescence is, in fact, a particularly compelling period of development, in which biological, psychological and social system undergo marked developmental changes (Cicchetti \&
Rogosch, 2002). Such changes could indicate that the same disorder, at different ages, could result from various etiological paths and, in certain cases, exacerbated by gender (Copeland et al., 2009). For example, childhood depression would seem to undergo more changes in girls, during puberty, than boys. This could support the hypothesis of a possible focus on chronological and generational continuity in research trials. Furthermore, the group of heterogeneous disorders in a single diagnostic category complicates the analysis of predictiveness, such as, for example, the inclusion of all anxiety disorders in one, single diagnostic label. In the analysis of the continuity, this unification may hide substantial individual differences and thus affect the results; as well as, for example, excluding from the analysis the co-occurrence of different disorders and their comorbidity. It seems, therefore, still necessary to try to answer some questions regarding the possible relationship of continuity or discontinuity between a psychiatric disorder diagnosed for the first time in childhood and adulthood disorders, in the light of the analysis on the results of longitudinal studies begun in recent years: what kind of continuity is it? Longitudinal studies which take into account the influences of risk and protective factors on the odds of maintaining a disorder from childhood to adulthood are, therefore, still needed.

\section{References}

American Psychiatric Association (2013). Diagnostic and statistical manual of mental disorders (DSM-5®). Arlington, VA: American Psychiatric Pub.

Ammaniti, M., Lucarelli, L., Cimino, S., \& D’Olimpio, F. (2008). Psicopatologia dello sviluppo e anoressia infantile: continuità omotipica ed eterotipica. NÓOৎ, 3, 197-216.

Anderluh, M.B., Tchanturia, K., Rabe-Hesketh, S., \& Treasure, J. (2003). Childhood obsessive-compulsive personality traits in adult women with eating disorders: defining a broader eating disorder phenotype. American Journal of Psychiatry, 160, 242-247.

Biro, F. M., \& Wien, M. (2010). Childhood obesity and adult morbidities. The American Journal of Clinical Nutrition, 91(5), 1499S-1505S.

Bleiberg, E. (2004). Treating personality disorders in children and adolescents: A relational approach. New York: Guilford Press.

Bulik, C.M., Prescott, C.A., \& Kendler, K.S. (2001). Features of childhood sexual abuse and the development of psychiatric and substance use disorders. British Journal of Psychiatry, 179, 444-449.

Caspi, A. (2000). The child is father of the man: personality continuities from childhood to adulthood. Journal of Personality and Social Psychology, 78 (1), 158-172.

Castagnini, A., Foldager, L., Caffo, E. \& Thomsen, P.H. (2016). Early-adult outcome of child and adolescent mental disorders as evidenced by a national-based case register survey. European Psychiatry, 38, 45-50.

Caviglia, G., Perrella, R., Sapuppo, W., \& Del Villano, N. (2010). La ricerca in psicoterapia: il contributo del Gruppo di lavoro della Cattedra di Psicologia Dinamica (base) della 
Seconda Università di Napoli. Research in Psychotherapy: Psychopathology, Process and Outcome, 2 (13), 32-52.

Caviglia G., \& Zarrella I. (2011). Continuità e discontinuità tra psicopatologia dell'età infantile e dell'età adulta: una review sulla visione prospettica. Psichiatria dell'Infanzia e dell'Adolescenza, 78 (2), 401-414.

Caviglia G., \& Zarrella I. (2013). Continuità e discontinuità tra psicopatologia dell'età infantile e dell'età adulta: una review sulla visione retrospettiva. Psichiatria dell'Infanzia e dell'Adolescenza, 80 (3), 602-614.

Cicchetti, D. (2010). Developmental psychopathology. In S.L.E.M. Lamb, A.M. Freund \& R. M. Lerner (Eds.), The handobook of life-span development, Vol. II (pp. 511-590). New Jersey: John Wiley \& Sons.

Cicchetti, D., \& Rogosch, F.A. (2002). A developmental psychopathology perspective on adolescence. Journal of consulting and clinical psychology, 70(1), 6.

Copeland, W.E., Shanahan, I., Costello, J.E., \& Angold, A. (2009). Childhood and Adolescent Psychiatric Disorders as Predictor of Young Adult Disorders. Archives of General Psychiatry, 66 (7), 764-772.

Copeland, W.E., Wolke, D., Shanahan, L., \& Costello, E.J. (2015). Adult functional outcomes of common childhood psychiatric problems: a prospective, longitudinal study. JAMA Psychiatry, 72(9), 892-899.

Costello, E.J., Mustillo, S., Erkanli, A., Keller, G., \& Angold, A. (2003). Prevalence and Development Psychiatric Disorders in Childhood and Adolescence. Archives of General Psychiatry, 60, 837-844.

Del Villano, N., Perrella, R., Bisogno, S., \& Caviglia, G. (2014). Working memories abilities, attachment relationships and learning process in children of primary school age: An empirical research. Research in Psychoterapy: Psychopathology, Process and Outcome, 17 (1), 21-32.

Deschamps, P.K., \& Vreugdenhil, C. (2008). Stability of borderline personality disorder from childhood to adulthood: a literature review. Tijdschr Psychiatry, 50 (1), 33-41.

Dunn, E.C., Nishimi, K., Powers, A., \& Bradley, B. (2016). Is developmental timing of trauma exposure associated with depressive and post-traumatic stress disorder symptoms in adulthood? Journal of Psychiatric Research, 84, 119-127.

Elkins, I.J., McGue, M., Malone, S., \& Iacono, W.G. (2004). The Effect of Parental Alcohol and Drug Disorders on Adolescent Personality. American Journal of Psychiatry, 161, 670-676.

Ferdinand, R.F., Dieleman, G., Ormel, J., \& Verhulst, F.C. (2007). Homotypic versus heterotypic continuity of anxiety symptoms in young adolescents: evidence for distinctions between DSM-IV subtypes. Journal of Abnormal Child Psychology, 35, 325-333.

Golier, J.A., Yehuda, R., Bierer, L.M., Mitropoulou, V., New, A.S., Schmeidler, J., Silverman, J.M., \& Siever, L.J. (2003). The relationship of borderline personality disorder to posttraumatic stress disorder and traumatic events. American Journal of Psychiatry, 160, 2018-2024.

Helgeland, M.I., Kjelsberg, E., \& Torgersen, S. (2005). Continuities between emotional and disruptive behaviour disorders in adolescence and personality disorders in adulthood. American Journal of Psychiatry, 162, 1941-1947.

Hofstra, M.B., Van der Ende, J., \& Verhulst, F.C. (2002). Child and adolescent problems predict DSM-IV disorders in adulthood: a 14-year follow-up of a Dutch epidemiological sample. Journal of the American Academy of Child \& Adolescent Psychiatry, 41(2), 182-189.
Jans, T., Schneck-Seif, S., Weigand, T., Schneider, W., Ellgring, H., Wewetzer, C., \& Warnke, A. (2008). Longterm outcome and prognosis of dissociative disorder with onset in childhood or adolescence. Child and Adolescent Psychiatry and Mental Health, 2(1), 19.

Johnson, J.G., Cohen, P., Brown, J., Smailes, E.M. \& Bernstein, D. P. (1999a). Childhood maltreatment increases risk for personality disorders during early adulthood. Archives of General Psychiatry, 56, 600-606.

Johnson, J.G., Cohen, P., Chen, H., Kasen, S. \& Brook, J.S. (2006). Parenting behaviors associated with risk for offspring personality disorder during adulthood. Archives of General Psychiatry, 63, 579-587.

Johnson, J.G., Cohen, P., Kasen, S. \& Brook, J.S. (2002). Eating disorders during adolescence and the risk for physical and mental disorders during early adulthood. Archives of General Psychiatry, 59, 545-552.

Johnson, J.G., Cohen, P., Skodol, A.E., Oldham, J.M., Kasen, S., \& Brook, J. S. (1999b). Personality disorders in adolescence and risk of major mental disorders and suicidality during adulthood. Archives of General Psychiatry, 56, 805-811.

Kar, N., Mohapatra, P.K., Nayak, K.C., Pattanaik, P., Swain, S.P. \& Kar, H.C. (2007). Post-traumatic stress disorder in children and adolescents one year after a super-cyclone in Orissa, India: exploring cross-cultural validity and vulnerability factors. BMC Psychiatry, 7(1), 1.

Kasen, S., Cohen, P., Skodol, A.E., Johnson, J.G. \& Brook, J.S. (1999). Influence of child and adolescent psychiatric disorders on young adult personality disorder. American Journal of Psychiatry, 156, 1529-1535.

Kasen, S., Cohen, P., Skodol, A.E., Johnson, J.G., Smailes, E. \& Brook, J.S. (2001). Childhood depression and adult personality disorder: alternative pathways of continuity. Archives of General Psychiatry, 58, 231-236.

Kent, A., Waller, G. \& Dagnan, D. (1999). A greater role of emotional than physical or sexual abuse in predicting disordered eating attitudes: the role of mediating variables. International Journal of Eating Disorders, 25(2), 159-167.

Kim-Cohen, J., Caspi, A., Moffitt, T.E., Harrington, H., Milne, B.J. \& Poulton, R. (2003). Prior juvenile diagnoses in adults with mental disorder: developmental follow-back of a prospective-longitudinal cohort. Archives of General Psychiatry, 60, 709-717.

Labey, B.B. (2015). Why are children who exhibit psychopathology at high risk for psychopathology and dysfunction in adulthood? JAMA Psychiatry, 72(9), 865-866.

Lahey, B.B., Zald, D.H., Hakes, J.K., Krueger, R.F., \& Rathouz, P.J. (2014). Patterns of heterotypic continuity associated with the cross-sectional correlational structure of prevalent mental disorders in adults. JAMA psychiatry, 71(9), 989-996.

Lenzenweger, M.F. (1999). Stability and change in personality disorder features. The longitudinal study of personality disorders. Archives of General Psychiatry, 56, 1009-1015.

Levi, G., \& Romani, M. (1999). Continuità e discontinuità tra psicopatologia dell'età evolutiva e dell'età adulta. $N O ́ O \varsigma$, 5, 3-14.

Lewis, M., \& Volkmar, F.R. (2002). Borderline disorders in children and adolescents. In: S.L. M. Lewis (ed.), Child and adolescent psychiatry: a comprehensive textbook, 3rd edition (pp. 836-841). Philadelphia, PA: Lippincott Williams \& Wilkins Publishers.

Loeber, R., \& Farrington, D.P. (1997). Strategies and yields of longitudinal studies on antisocial behavior. In: S.L.M.D. 
Stoff, J. Breiling, \& J.D. Maser (Eds), Handbook of antisocial behavior (pp. 125-139). New York: Wiley.

Maughan, B., \& Rutter, M. (1997). Retrospective reporting of childhood adversity: issues in assessing longterm recall. Journal of Personal Disorder, 11, 19-33.

Maughan, B., \& Kim-Cohen, J. (2005). Continuities between childhood and adult life. The British Journal of Psychiatry, 187, 301-303.

McGue, M. (2016). Cohort studies and the development of psychopathology: commentary on the Great Smoky Mountain Study. Social psychiatry and psychiatric epidemiology, 51(6), 799-801.

McLean, L.M. \& Gallop, R. (2003). Implications of childhood sexual abuse for adult borderline personality disorder and complex posttraumatic stress disorder. American Journal of Psychiatry, 160, 369-371.

Mikolajewski, A.J., Taylor, J., \& Iacono, W.G. (2017). Oppositional defiant disorder dimensions: genetic influences and risk for later psychopathology. Journal of Child Psychology and Psychiatry, 58(6), 702-710. DOI: 10.1111/jcpp.12683.

Minde, K. \& Minde, R. (2002). Effect of disordered parenting on the development of children. In: S.L.M. Lewis (Ed.), Child and adolescent psychiatry: a comprehensive textbook, 3 rd edition (pp. 459-474). Philadelphia: Lippincott Williams \& Wilkins Publishers.

Moss, H.B., Lynch, K.G., Hardie, T.L. \& Baron, D.A. (2002). Family functioning and peer affiliation in children of fathers with antisocial personality disorder and substance dependence: associations with problem behaviors. American Journal of Psychiatry, 159, 607-614.

Perrella, R., Semerari, A. \& Caviglia, G. (2013). Metacognition, borderline pathology and psychotherapeutic change: a single-case study. Research in Psychotherapy: Psychopathology, Process and Outcome, 16(2), 102-108.

Perrella, R., Del Villano, N., \& Caviglia, G. (2016). Referential activity, dissociation, psychopathology and psychotherapy. Research in Psychotherapy: Psychopathology, Process and Outcome, 19(2), 165-171.

Rubino, A., Croce Nanni, R. \& Siracusano, A. (2008). Traumi dell'età dello sviluppo e spettro schizofrenico. NÓOS, 3 , 237-254.

Rutter, M. (2005). How the environment affects mental health. British Journal of Psychiatry, 186, 4-6.

Rutter, M., Kim-Cohen, J. \& Maughan, B. (2006). Continuities and discontinuities in psychopathology between childhood and adult life. Journal of Child Psychology and Psychiatry, 47 (3/4), 276-295.

Sartor, R., \& Salcuni, S. (2017). From attention deficit/hyperactivity disorder to borderline personality disorder: a developmental integrated perspective. EC Psychology and Psychiatry, 3(3), 69-81.

Siracusano, A., \& Rubino, I.A. (2010). Continuity and discontinuity in psychopathology: the converging role of risk factors and resilience for the pathways toward schizophrenia. Giornale Italiano di Psicopatologia, 16, 135-137.

Skovgaard, A.M., Olsen, E.M., Christiansen, E., Houmann, T., Landorph, S.L., Jørgensen, T. \& CCC 2000 Study Group (2008). Predictors ( $0-10$ months) of psychopathology at age $1 \frac{1 / 2}{2}$ years - a general population study in The Copenhagen Child Cohort CCC 2000. Journal of Child Psychology and Psychiatry, 49(5), 553-562.

Skodol, A.E., Johnson, J.G., Cohen, P., Sneed, J.R. \& Crawford, T.N. (2007). Personality disorder and impaired functioning from adolescence to adulthood. British Journal of Psychiatry, 190, 415-420.

Stein, A., Lehtonen, A., Harvey, A.G., Nicol-Harper, R. \& Craske, M. (2009). The influence of postnatal psychiatric disorder on child development. Is maternal preoccupation one of the key underlying processes? Psychopathology, 42, $11-21$.

Torres Pérez, I., Del Rio Sànchez, C. \& Borda Mas, M. (2008). MCMI-II: borderline personality disorders in anorexia and bulimia nervosa. Psicothema, 20(1), 138-143.

Turk, J., Graham, P. \& Verhulst, C. (2007). Child and adolescent psychiatry. A developmental approach. New York: Oxford University Press.

Wallerstein, J.S., \& Corbin, S.B. (2002). The Child and the vicissitudes of Divorce. In S.L.M. Lewis (ed.), Child and adolescent psychiatry: a comprehensive textbook, 3rd edition (pp. 1187-1195). Philadelphia: Lippincott Williams \& Wilkins Publishers.

Weibel, S., Vidal, S., Olié, E., Hasler, R., Torriani, C., Prada, P., ... \& Huguelet, P. (2017). Impact of child maltreatment on meaning in life in psychiatric patients. Psychiatry Research, 251, 204-211.

Weller, E.B., Weller, R.A., Benton, T., \& Wiltsie Pugh, J.J. (2002). Grief. In S.L. M. Lewis (Eds), Child and adolescent psychiatry: a comprehensive textbook, 3rd edition (pp. 453-458). Philadelphia: Lippincott Williams \& Wilkins Publishers.

Wolff, S. (2002). Moral Development. In S.L.M. Lewis (Eds), Child and adolescent psychiatry: a comprehensive textbook, 3rd edition (pp. 256-265). Philadelphia: Lippincott Williams \& Wilkins Publishers.

Zanarini, M.C., Frankenburg, F.R., Hennen, J. \& Silk, K.R. (2003). The longitudinal course of borderline psychopathology: 6-year prospective follow-up of the phenomenology of borderline personality disorder. American Journal of Psychiatry, 160, 274-283.

Zarrella, I., Lonigro, A., Perrella, R., Caviglia, G. \& Laghi, F. (2016). Social behaviour, socio-cognitive skills and attachment style in school-aged children: what is the relation with academic outcomes? Early Child Development and Care. DOI: $10.1080 / 03004430.2016 .1266486$.

Zero-To-Three (2008). CD:0-3R. Classificazione diagnostica della salute mentale e dei disturbi di sviluppo dell'infanzia. Roma: Fioriti Editore. 